\title{
Postnatal Acquired Toxoplasmosis Patients in an Infectious Diseases Reference Center
}

Cassius Schnell Palhano Silva ${ }^{1}$, Elizabeth de Souza Neves ${ }^{1}$, Eliezer Israel Benchimol ${ }^{2}$ and Danielle Ribeiro de Moraes ${ }^{3}$ ${ }^{1}$ Infectious Diseases Department - Evandro Chagas Clinical Research Institute / FIOCRUZ; Reference Centre for Ophthalmic Infections Evandro Chagas Clinical Research Institute / FIOCRUZ; ${ }^{3}$ Health Surveillance Professional Education Laboratory - Joaquim Venâncio Polytechnical Health School / FIOCRUZ; Rio de Janeiro, RJ, Brazil

\begin{abstract}
Infection caused by Toxoplasma gondii, toxoplasmosis, is one of the most frequent zoonoses in the world; it normally affects both genders equally. Humans are one of several possible intermediate hosts, and the disease is oligosymptomatic in most cases. Vertical transmission is an important cause of fetal malformation and sequels in newborns. Approximately $\mathbf{1 0 \%}$ of postnatal cases present multiple manifestations, ranging from low fever and mild lymphadenopathy to severe encephalitis. In moderate cases, lesions such as retinochoroiditis may emerge during acute infection or even years later. We analyzed 313 cases of toxoplasmosis from 1992 to 2004, including 261 acute cases. Most patients were women (68.1\%), and 39\% of these were pregnant. Among acute infection cases, $64.8 \%$ presented symptomatic disease; the most frequent manifestations were lymphadenomegaly (59.8\%), fever (27.2\%), headache $(10.7 \%)$, asthenia (10\%), weight loss $(8.4 \%)$, myalgia (8\%), retinochoroiditis $(3.4 \%)$ and hepatosplenomegaly (1.5\%). Although ocular lesions by $T$. gondii are well documented as a possible consequence of postnatal infection, two patients developed retinochoroiditis only two years after primary infection. This demonstrates the need for toxoplasmosis case surveillance, even long after acute manifestations.
\end{abstract}

Key-Words: Toxoplasmosis, Toxoplasma gondii, survey, clinical presentation, retinochoroiditis.

Toxoplasmosis, one of most common existing zoonoses, is caused by Toxoplasma gondii (Nicolle \& Manceaux, 1908)[1], a protozoan that has an heteroxenous life cycle and is able to infect various mammal and bird species through different transmission pathways, though felines are the definitive host [2-5]. It has a cosmopolitan distribution; serological surveys have demonstrated a vast range, affecting many countries, geographic areas and ethnic groups.

Variations in prevalence may be due to regional differences in environmental, demographic, culture and socio-economic factors. In central France, where meat consumption starts early in life, seropositivity is near $90 \%$, with a seroconversion rate near to that found in El Salvador [3]. In the USA, an average prevalence of $22.5 \%$ is estimated, ranging from 17.5 to $29.2 \%$ [6,7]. In Austria, where newborn toxoplasmosis surveillance was introduced in 1975, a study of pregnant women showed a $30 \%$ seroprevalence [8]. In Brazil, several descriptive studies show different serologic seroprevalences: in the mid-west and north, 54 and 75\% respectively [9]; 80.4\% in an indigenous group in the state of Mato Grosso [10] and from 66 to 75\% in rural populations in the south (state of Paraná) [11]; from 77.5 to $58.9 \%$ soroprevalence among pregnant women in an urban region of São Paulo [12]; from 23 to $84 \%$ in Campos dos Goytacazes (northern Rio de Janeiro State, in the Brazilian southeast)[13] and 68.4\% among primary school students in the city of Rio de Janeiro [14]. A progressive rise in seropositivity with age has been seen in children, adolescents and pregnant women in Fortaleza (northeast Brazil), ranging

Received on 19 May 2008; revised 1 October 2008.

Address for correspondence: Dr. Cassius Schnell Palhano Silva. Av. Alm. Ari Parreiras 301/1501. Zip Code: 24230-320 Niterói - RJ, Brazil. E-mail address: cassius.schnell@ensp.fiocruz.br.

The Brazilian Journal of Infectious Diseases

2008;12(5):438-441 (C) 2008 by The Brazilian Journal of Infectious Diseases and Contexto Publishing. All rights reserved. from 22.8 to $71.5 \%$ [15]; also in the Northeast, in the city of Recife, a seroprevalence of $79 \%$ for men and $63.4 \%$ for women was found among blood donors [16]. The increase in incidence of toxoplasmosis has shown to be proportional to age, with an estimated rate of serological conversion of $10 \%$ among 0 5 year-olds, $1 \%$ among $6-20$ year-olds, and $0.3 \%$ for people above 20 years old [3]. Along with mother-to-child transmission, other important transmission paths have been reported in epidemics and high prevalence regions, such as contaminated water sources and raw meat intake [5,13,17-19].

In humans, only $10 \%$ of infections appear to be symptomatic [7], and the disease has various manifestations, depending on individual health status during infection (pre or post-born, immunodeficiency). Toxoplasmosis can present as an acute-fever disease, associated or not with rash, myalgia, headache, prostration, pneumonia, and frequently, lymphadenopathy; hepatic and myocardial impairment are rare; encephalitis, mostly in immunodepressed patients; in newborn infections and abortion, malformations and posterior sequels may occur, e.g., retinochoroiditis, a lesion associated with toxoplasmosis.

\section{Material and Methods}

We made a retrospective analysis of the clinical conditions of toxoplasmosis patients attended at IPEC/Fiocruz (Instituto de Pesquisa Clínica Evandro Chagas - Evandro Chagas Clinical Research Institute - Oswaldo Cruz Foundation), an infectious diseases reference center situated in the city of Rio de Janeiro, covering a12-year period (1992-2004). This health service is part of a universal-access national health system, offering, among other services, specialized care for toxoplasmosis patients from Rio de Janeiro and part of its metropolitan area population (approximately 9,285,456 inhabitants). Secondary data were obtained from patients' files; the variables that were collected included gender, age, signs and symptoms, pregnancy situation, ophthalmic condition, IgM and IgG anti- 
toxoplasmosis titers, and treatment scheme. While IPEC is one of few infectious diseases centers attending this region, toxoplasmosis diagnosis and treatment can be performed not only in such reference centers, but also in other public and private services.

\section{Inclusion Criteria}

This casuistic included patients with acquired acute toxoplasmosis, symptomatic or not, confirmed by positive serology for IgM and IgG antibodies, detected by antibodyenzymatic tests ELFA (Enzyme Linked Fluorescent Assay VIDAS TOXO IgG II (TXG) and IgM II (TXM) kits) or ELISA (Enzyme-Linked Immunosorbent Assay - TOXOPLASMA IgG and IgM ENZYWELL kits), depending on the method available at the time of examination. For evaluation of late retinochoroiditis, patients were followed up for a period of two to five years. Late retinochoroiditis was considered when an active retinal lesion appeared six months after the remission of acute disease, without previous ocular lesions in the same eye.

\section{Case Management Protocol}

Patients attended for the first time at IPEC are examined by an infectious-diseases specialist for general evaluation, and treatment, if necessary. On this occasion, anti-toxoplasmosis serology is performed at the institution to confirm each case. Each person is taken to the Reference Center for Ophthalmic Infections at IPEC in order to be examined by funduscopy. After the first evaluation, each patient is followed up by an infectious diseases specialist; a second funduscopy is indicated six months later, and then annually. Standard treatment for acute disease includes sulfadiazine and pirimetamine, associated with folinic acid, and prednisone is included when retinochoroiditis is evident, to minimize inflammatory reaction. Spiramycin is used in cases of pregnancy, to prevent mother-to-child transmission of Toxoplasma gondii.

\section{Statistical Analysis}

Descriptive statistics were used to evaluate variables of interest, such as gender, age and clinical manifestations. We used the Student- $t$ test to compare means and the c2 test to make associative analyses (P-values $<0.05$ were considered significant). All statistics were performed using SPSS version 11 (SPSS Inc., Chicago, IL, USA).

\section{Results}

During the study period, 313 patients were attended at the toxoplasmosis outpatient service of IPEC. Among those, 261 presented acute infection by Toxoplasma gondii based on serology. Most patients were women (68.1\% - 213/313), which is probably explained by the fact that many pregnant women are referred to IPEC due to positive serology found during pre-natal follow up. The group of pregnant women represents $39 \%(83 / 213)$ of all women attended at the service. Among acute cases, females accounted for $65.5 \%$ (171/261), and 27.2\% (71/261) during pregnancy.

The mean age of all patients was 26.2 years old (median= 26; sd=12.19). Among men, the mean age was 21.98 years old (median=18; $\mathrm{sd}=13.12$ ), while in the female group it was significantly higher $(\mathrm{t}=-4.311 ; \mathrm{p}<0.01)$, being 28.21 years old (median= 27; sd= 11.23).

At the beginning of the follow up, signs and symptoms were presented by $64.8 \%$ of patients with acute infection (169/ 261). Lymphadenopathy was the most prevalent manifestation, appearing in 59.8\% (156/261) of the cases. Other common signs and symptoms were fever (27.2\% - 71/261), headache (10.7\% $28 / 261)$, weakness (10\% - 26/261), weight loss (8.4\% - 22/261), myalgia (8\% - 21/261), retinochoroiditis (2.7\% - 7/261) and hepatosplenomegaly (1.5\% - 4/261). Besides the seven initial cases of retinochoroiditis that occurred during acute disease, another two patients acquired late retinal lesions, developed at least two years after the primary infection, which increases the prevalence of postnatal-acquired ocular toxoplasmosis to $3.4 \%(9 / 261)$. The distribution of signs and symptoms is presented in Table 1.

In addition, associative analysis of acute cases shown a relationship between gender and clinical manifestations $\left(\chi^{2}=\right.$ 48.916; $\mathrm{p}<0.01$ ) in this population; women presented more clinical symptoms, even when pregnant patients were excluded from analysis $\left(\chi^{2}=6.846 ; \mathrm{p}<0.01\right)$.

\section{Discussion}

Toxoplasmosis is one of the most disseminated protozoa infections worldwide; it has been described in 200 different species of vertebrates [20]. Human infection was identified for the first time in 1923; early in the 1940s, mother-to-child transmission and congenital toxoplasmosis were already recognized. In the following years, other changes related to congenital toxoplasmosis were found in newborns and children, such as encephalomyelitis and brain calcifications, neurological disturbances, hydrocephaly and retinochoroiditis [21].

Many pregnant women referred to our service were positive for anti-toxoplasmosis IgM and negative for IgG, which configures a previous infection, but not necessarily a recent one. Considering that toxoplasmosis serology is a standard procedure in pre-natal care in Brazil, this fact reveals that some services involved in pregnancy assistance are not able to interpret a serological test properly, leading to a wrong or a doubtful diagnosis. On the other hand, a positive serological test for anti-toxoplasmosis IgM demands an appropriate investigation, since residual anti-toxoplasmosis IgM antibodies can persist for months or even years [22,23] after acute disease. In this case, an IgG avidity test could aid help provide a correct diagnosis, as a temporal marker of infection, through verification of the functional affinity of these antibodies, which makes it possible to distinguish between past and recent infection [24,25]. This test is especially useful when a pregnant woman presents both IgG and IgM positive 
Table 1. Distribution of acute toxoplasmosis manifestations by age and gender, in number and percentage (in parentheses for each group).

\begin{tabular}{cccccccccc}
\hline $\begin{array}{c}\text { Age } \\
\text { (years) }\end{array}$ & N & $\begin{array}{c}\text { Lympha- } \\
\text { denopathy }\end{array}$ & Fever & Headache & Weakness & $\begin{array}{c}\text { Weight } \\
\text { loss }\end{array}$ & Myalgia & $\begin{array}{c}\text { Retino } \\
\text { choroiditis }\end{array}$ & $\begin{array}{c}\text { Hepato- } \\
\text { splenomegaly }\end{array}$ \\
\hline $0-10$ & 26 & $24(92.3 \%)$ & $7(26.9 \%)$ & $1(3.8 \%)$ & $1(3.8 \%)$ & 0 & $1(3.8 \%)$ & 0 & $1(3.8 \%)$ \\
$11-20$ & 68 & $45(66.2 \%)$ & $20(29.4 \%)$ & $8(11.8 \%)$ & $7(10.3 \%)$ & $6(8.8 \%)$ & $3(4.4 \%)$ & $1(1.5 \%)$ & $1(1.5 \%)$ \\
$21-30$ & 85 & $39(45.9 \%)$ & $17(20 \%)$ & $9(10.6 \%)$ & $5(5.9 \%)$ & $5(5.9 \%)$ & $3(3.5 \%)$ & $3(3.5 \%)$ & 0 \\
$31-40$ & 47 & $26(55.3 \%)$ & $11(23.4 \%)$ & $3(6.4 \%)$ & $6(12.8 \%)$ & $5(10.6 \%)$ & $5(10.6 \%)$ & $1(2.1 \%)$ & $1(2.1 \%)$ \\
$>40$ & 35 & $22(62.9 \%)$ & $16(45.7 \%)$ & $7(20 \%)$ & $7(20 \%)$ & $6(17.1 \%)$ & $9(25.7 \%)$ & $4(11.4 \%)$ & $1(2.9 \%)$ \\
Male & 88 & $77(87.5 \%)$ & $39(44.3 \%)$ & $15(17 \%)$ & $17(19.3 \%)$ & $15(17 \%)$ & $9(10.2 \%)$ & $6(6.8 \%)$ & $4(4.5 \%)$ \\
Female & 173 & $79(45.7 \%)$ & $32(18.5 \%)$ & $13(7.5 \%)$ & $9(5.2 \%)$ & $7(4 \%)$ & $12(6.9 \%)$ & $3(1.7 \%)$ & 0 \\
Total & 261 & $156(59.8 \%)$ & $71(27.2 \%)$ & $28(10.7 \%)$ & $26(10 \%)$ & $22(8.4 \%)$ & $21(8 \%)$ & $9(3.4 \%)$ & $4(1.5 \%)$ \\
\hline
\end{tabular}

tests at the beginning of pregnancy, so that invasive tests and unnecessary medication can be avoided [26,27].

Ocular lesions due to toxoplasmosis in adults were first described in 1952, and during the 1950s and 1960s several cases were identified, many of them consistent with postnatal infection [28]. However, such lesions were often considered a product of congenital disease, with later manifestation or reactivation of old retinal scars, and so it was up until the 1990's.

Many postnatal primary cases presenting ophthalmic manifestations have been described recently [29-31]. Ocular toxoplasmosis accounts for about $30 \%$ to $60 \%$ of all retinochoroiditis cases [3,16]; it can appear as a sudden retinitis with inflammation that resolves after one or two months, or as a chronic retinitis active for months, resulting from cellular necrosis due to tachyzoite proliferation. Though congenital and acquired lesions look the same in funduscopy, some studies point to a better prognosis for cases of acute-acquired toxoplasmosis. It is possible that different $T$. gondii strains play an important role in toxoplasmosis pathogenesis, but the severity of lesions may also depend on the immune response of the host. Some authors suggest that patients with congenital disease have a diminished immune response to antigens of $T$. gondii and, as a consequence of some kind of tolerance to parasite infection. This could be due to parasitic antigens in the organism during lymphocyte maturation in a developing thymus [32].

Several studies show that approximately $3 \%$ of acute toxoplasmosis cases evolve to ocular illness [30]. This prevalence was also found in our study group. In addition to the patients who developed retinochoroiditis during acute disease, two late cases developed, both in middle-aged men and two years after primary infection. Other cases of late toxoplasma retinochoroiditis have also been reported. In 1990, a study made in Erechim (a southern Brazilian city) followed 131 people seropositive for toxoplasmosis and who did not present ocular lesions. After seven years, 11 of them had evolved to late toxoplasma retinochoroiditis [21].

Despite the high incidence of $T$. gondii infection, symptomatic disease occurs at a low frequency. Among symptomatic cases of toxoplasmosis, about 90\% develop persistent lymphadenopathy, mild fever and asthenia. Since signs and symptoms of toxoplasmosis are non-specific, it may be misinterpreted as a variety of conditions, such as flu, mononucleosis and cytomegalovirus infection. The illness can have spontaneous remission after a few weeks; thus treatment is not mandatory in mild acute cases [7,33,34]. However, in more severe or persistent cases, the use of antimicrobial and other adjunct drugs may be necessary. Some rare and severe forms of toxoplasmosis, such as encephalitis, occur more commonly in immunocompromised persons (AIDS and transplanted patients). Clinical disease manifestations and their frequency in our group were similar to what has been found in other studies of symptomatic toxoplasmosis $[7,35]$.

\section{Conclusions}

Though toxoplasmosis is one of the most common parasitic infections, few cases develop to symptomatic disease. As it has been previously reported, data from a reference center (such as ours), may not represent the general population, yet our findings were similar to those reported in previous studies. Two exceptions emerged from our statistical analysis, which showed gender differences: while men presented symptoms at a younger age, women appeared to have more clinical symptoms. These facts should be regarded carefully, as this was not a population-based study.

Although toxoplasmosis is usually considered a benign and self-limiting illness, late and permanent lesions may occur, such as toxoplasma retinochoroiditis. Consequently, acute cases may need to be treated and followed up, in order to minimize the risks of such lesions. Medical staff must then be alert to this infection and its consequences, even after acute infection and remission. This concept was confirmed by the two cases of ocular impairment that we found, which were properly diagnosed and treated due to the management case protocol of the IPEC Reference Centre.

On the other hand, an initial examination of reasons for referral of cases to IPEC revealed problems in toxoplasmosis diagnosis and assistance by other health service providers. This fact, considering the magnitude of this disease in Brazil, 
means that we need to discuss surveillance strategies for toxoplasmosis. The protocol that we used could be adapted to other health services.

\section{References}

1. Nicolle C., Manceaux L. Sur un protozoaire nouveau du gondi. Arch Inst Pasteur Tunis 1909;2:97-103.

2. Coutinho S.G. Toxoplasma gondi e toxoplasmose. In: Rey L. ed. Parasitologia. 2a ed. Rio de Janeiro: Editora Guanabara Koogan; 1991. p. 274-85.

3. Frenkel J.K. Toxoplasmose. In: Veronesi R., Focaccia R. eds. Tratado de infectologia. $2^{a}$ ed. São Paulo: Editora Atheneu; 2002. p. $1310-25$.

4. Neto V.A., Barone A.A. Toxoplasmose. In: Neto V.A., Baldy J.L.S. eds. Doenças transmissíveis. $3^{a}$ ed. São Paulo: Editora Sarvier; 1991. p. 831-43.

5. Tenter A.M., Heckeroth A.R., Weiss L.M. Toxoplasma gondii: from animals to humans. Int J Parasitol 2001 Feb;31(2):217-20.

6. Jones J.L., Kruszon-Moran D., Wilson M., et al. Toxoplasma gondii infection in the United States: seroprevalence and risk factors. Am J Epidemiol 2001 Aug 15;154(4):357-65.

7. Montoya J.G., Liesenfeld O. Toxoplasmosis. Lancet 2004Jun;363:1965-76.

8. Sukthana Y. Difference of Toxoplasma gondii antibodies between Thai and Austrian pregnant women. Southeast Asian J Trop Med Public Health 1999 Mar;30(1):38-41.

9. Ricciardi I.D., Sabroza P.C., Sandoval E.D., Mayrink W. Seroepidemiological study on the prevalence human toxoplasmosis in Brazil. Rev Microbiol 1978;9:181-7.

10. Amendoeira M.R.R., Sobral C.A., Teva A., et al. Inquérito sorológico para a infecção por Toxoplasma gondii em ameríndios isolados, Mato Grosso. Rev Soc Bras Med Trop 2003 NovDec;36(6):671-6.

11. Garcia J.L., Navarro I.T., Ogawa L., et al. Soroprevalência, epidemiologia e avaliação ocular da toxoplasmose humana na zona rural de Jaguapitã (Paraná), Brasil. Rev Panam Salud Publica 1999 Sep;6(3):157-63.

12. Guimarães A.C.S., Kawarabayashi M.M., Tolezano J.E., Andrade Jr H.F. Regional variation in toxoplasmosis seronegativity in the São Paulo metropolitan region. Rev Inst Med Trop Sao Paulo 1993 Nov-Dec;35(6):479-83.

13. Bahia-Oliveira L.M.G., Jones J.L., Azevedo-Silva J., et al. Highly endemic, waterborne toxoplasmosis in north Rio de Janeiro state, Brazil. Emerg Infect Dis 2003 Jan;9(1):55-62.

14. Souza W.J., Coutinho S.G., Lopes C.W., et al. Epidemiological aspects of toxoplasmosis in schoolchildren residing in localities with urban or rural characteristics within the city of Rio de Janeiro, Brazil. Mem Inst Oswaldo Cruz 1987 OctDec;82(4):475-82.

15. Rey L.C., Ramalho I.L.C. Seroprevalence of toxoplasmosis in Fortaleza, Ceará, Brazil. Rev Inst Med Trop S Paulo 1999 MayJun;41(3):171-4.

16. Coêlho R.A., Kobayashi M., Carvalho L.B. Prevalence of IgG antibodies specific to Toxoplasma gondii among blood donors in Recife, Northeast Brazil. Rev Inst Med Trop Sao Paulo 2003 Jul-Aug;45(4):229-31.

17. Aramini J.J., Stephen C., Dubey J.P., et al. Potential contamination of drinking water with Toxoplasma gondii oocyts. Epidemiol Infect 1999 Apr;122(2):305-15.
18. Bonametti A.M., Passos J.N., Silva E.M.K., Bortoliero A.L. Surto de toxoplasmose aguda transmitida através da ingestão de carne crua de gado ovino. Rev Soc Bras Med Trop 1996 JanFeb;30(1):21-5.

19. Choi W.Y., Nam H.W., Kwak N.H., et al. Foodborne outbreaks of human toxoplasmosis. J Infect Dis 1997;175:1280-2.

20. Acha P.N., Szyfres B. Toxoplasmosis. In: Acha P.N., Szyfres B. eds. Zoonosis $\mathrm{Y}$ enfermedades transmisibles comunes al hombre y a los animales: parasitosis. $3^{\mathrm{a}}$ ed. Washington, D.C.: OPS; 2003. p. 88-98.

21. Silveira C., Belfort R., Muccioli C., et al. A follow-up study of Toxoplasma gondii infection in southern Brazil. Am J Ophthalmol 2001 Mar;131(3):351-4.

22. Bobic B., Sibalic D., Djurkovic-Djakovic O. High levels of IgM antibodies specific for Toxoplasma gondii in pregnancy 12 years after primary toxoplasma infection. Gynecol Obstet Investig 1991;31(3):182-4.

23. Liesenfeld O., Press C., Montoya J.G., et al. False-positive results in immunoglobulin $\mathrm{M}$ (IgM) toxoplasma antibody tests and importance of confirmatory testing: the Platelia Toxo IgM test. J Clin Microbiol 1997;35(1):174-8.

24. Hedman K., Lappalainen M., Seppaia I., Makela O. Recent primary toxoplasma infection indicated by a low avidity of specific IgG. J Infect Dis 1989;159(4):736-40.

25. Lappalainen M., Koskela P., Koskiniemi M., et al. Toxoplasmosis acquired during pregnancy: improved serodiagnosis based on avidity of IgG. J Infect Dis 1993;167(3):691-7.

26. Remington J.S., Thulliez P., Montoya J.G. Recent developments for diagnosis of toxoplasmosis. J Clin Microbiol 2004;42(3):941-5.

27. Liesenfeld O., Montoya J.G., Kinney S., et al. Effect of testing for IgG avidity in the diagnosis of Toxoplasma gondii infection in pregnant women: experience in a US reference laboratory. J Infect Dis $2001 ; 183(8): 1248-53$.

28. Gilbert R.E., Stanford M.R. Is ocular toxoplasmosis caused by prenatal or postnatal infection? Br J Ophthalmol 2000 Feb;84(2):224-6.

29. Bosch-Driessen E.H., Rothova A. Recurrent ocular disease in postnatally acquired toxoplasmosis. Am J Ophthalmol 1999;128:421-5.

30. Holland G.N. Ocular toxoplasmosis: a global reassessment. Part I: epidemiology and course of disease. Am J Ophthalmol 2003 Dec;136(6):973-88.

31. Ongkosuwito J.V., Bosch-Driessen E.H., Kijlstra A., Rothova A. Serologic evaluation of patients with primary and recurrent ocular toxoplasmosis for evidence of recent infection. Am J Ophthalmol 1999 Oct;128(4):407-12.

32. Souza W.J., Coutinho S.G., Lopes C.W., et al. Epidemiological aspects of toxoplasmosis in schoolchildren residing in localities with urban or rural characteristics within the city of Rio de Janeiro, Brazil. Mem Inst Oswaldo Cruz 1987 OctDec;82(4):475-82.

33. Krick J.A., Remington J.S. Toxoplasmosis in the adult - an overview. N Engl J Med 1978;298(10):550-3.

34. Lynfield R., Guerina N.G. Toxoplasmosis. Pediatr Rev 1997;18(3):75-83.

35. Nogueira S.A., Moreira R.B., Pereira N.G. Toxoplasmose, diagnóstico e tratamento. JBM 1996;71(2):38-43. 